\title{
THE PSYCHOANALYTIC THOUGHT OF HÉLIO PELLEGRINO (1924-1988): INITIAL REFLECTIONS
}

\author{
Larissa Leão de Castro, \& Terezinha de Camargo Viana \\ Postgraduate program in Clinical Psychology and Culture, University of Brasília (Brazil) ${ }^{l}$
}

\begin{abstract}
This theoretical study is part of a doctoral thesis and aims to investigate how the psychoanalytic thinking of Hélio Pellegrino - the Brazilian psychoanalyst, poet and writer - is structured and its ethical and political implications in the formation of psychoanalysis. We note the importance of thematic research, since there is no scientific publication that has as its object of study a systematic analysis of the author's psychoanalytic production. Furthermore, investigations of this kind contribute to the establishment of a reference bibliography on psychoanalysis in Brazil. That said, this research was developed and completed through a study of a large part of his psychoanalytic production, which is under the custody of the personal archives of the Museum of Brazilian Literature, at the Casa Rui Barbosa Foundation (FCRB). In this work, we outline some elements of the analysis found in his work, whose focus is on reflecting on the epistemological, conceptual and practical foundations of psychoanalytic theory. It has, as a constant concern, the analysis of the problems that structure Brazilian society, observed through his own reading of the Oedipus complex, the constitution of subjectivity and the social pact, in general, and in Brazil, in particular. As such, he discusses the explicit commitment of psychoanalysis in transforming the serious social problems faced by Brazil, which are related to the serious structural problems of international capitalism, and which are also reflected in the problems of the development of psychoanalytic institutions around the world.
\end{abstract}

Keywords: Hélio Pellegrino, Oedipus complex, social pact, Brazil, subjectivation.

\section{Introduction}

This research is grounded within a political conjuncture of renewed authoritarianism and the advancement of a global ultra-right political project. These tendencies are represented, for example, by the US imperialism of the Trump administration and the barbarism of the Bolsonaro government here in Brazil. Both attempted to use the covid-19 pandemic as a pretext to permit genocide, seeking to destroy not only the elements that constitute a humanizing civilizing process, but also putting the continuity and respect for life and civilization at risk. In this social crisis, the study of researches and theorists who posit a civilizing process and the elements that structure these social symptoms is even more important, in view of the need to overcome this humanitarian catastrophe.

One of the fundamental authors in this regard is Hélio Pellegrino, a psychoanalyst, poet, and Brazilian writer. He should be considered an indispensable theoretician for anyone concerned with the theories of the civilizing process. Furthermore, his thought is indispensable around the theories he developed of the Oedipus complex in psychoanalysis, about the subjective and objective conditions that structure or break with a humanizing civilizing process and about the elements of articulation and solidarity between the social pact and the oedipal pact at a social and intrapsychic level.

It is worth mentioning that there has been a recognition of authors from different countries about the scope and depth of psychoanalytic production in Brazil and Argentina. However, this recognition is only an academic formality and there are few studies on the subject (Rivera, 2017, p.2). We note the importance of thematic research, since there is no scientific publication that has as its object of study a systematic analysis of the author's psychoanalytic production. In addition, research of this order contributes to the establishment of a reference bibliography on psychoanalysis in Brazil, as well as with

\footnotetext{
${ }^{1}$ The author of this article is grateful for the financial aid for doctoral research, of which this work was part, by the National Council for Scientific and Technological Development $(\mathrm{CNPq})$, a federal public agency that contributes to the dedication of researchers in the country to research aimed at the interest of Brazilian society and for publicizing the results achieved. I also thank Ciaran Leonard, for translating this text into English.

Correspondence concerning this article should be addressed to Larissa Leão. E-mail: larissa.leao.castro@gmail.com
} 
the consideration of the advances of psychoanalysis as critical thinking and on the theoretical repressions present in the revisionism observed within psychoanalytic institutions.

In order to complete the thesis of which this work is part, I spent some time at the Museum of Brazilian Literature, situated in the Casa Rui Barbosa Foundation (FCRB), in Rio de Janeiro, for a period of research into the author's personal files. I note how, in different works, Pellegrino looks at how an amnesia has developed around the most original elements in Freudian theory, its fundamental concepts, as well as contributing an analysis of the theme of revolutions that are found in culture - and which are present in the myths of Totem and Tabu and in other Freudian discoveries. This is in addition to developing a critical analysis of the fundamentals and basic concepts of psychoanalysis.

\section{The naturalization of violence by the alienating bad faith of apolitical psychoanalysis}

Here are some initial reflections that are part of this doctoral thesis about the psychoanalytic thinking of Hélio Pellegrino, and which encompass his theoretical, ethical and political contribution to psychoanalysis. It also treats of his defense of the relationship between psychoanalysis and the democratic rule of law, his struggle against the dictatorship (1964-1985) and against torture - which led to his arrest by agents of the country's military dictatorship.

Similarly, during the military regime, he was expelled from the Psychoanalytic Society of Rio de Janeiro (SPRJ) for defending the relationship between psychoanalysis and democracy. This expulsion was based on the activities he reflected upon, which involved reinforcing the need to read Freud in psychoanalytic institutions and thinking about why Freud was not read in most of them. They also included debates about didactic training practices, debates about the need for democratization in psychoanalytic institution, whose practice is marked by elitism and privilege. He further argued that they functioned practically as multinationals, enjoying the maintenance of elitist privileges while restricting themselves to serving this portion of the population - which does not have any foundation in psychoanalytic theory, but is an ideological use of it. This expulsion culminated in his request for this society to investigate and take a stand against the testimonies that it maintained, in silence, a torturer as a candidate for the role of psychoanalytical practitioner - which became known as the Amílcar Lobo case; and whose expulsion from the board of the society was only overturned by court order (Pellegrino, n.d., pair.36)

Obviously, for the author, the complicity of psychoanalytic institutions with the dictatorial government refers to the interests of the country's elite, which has nothing to do with the essence of psychoanalysis or its foundation, par excellence, but it has to do with class interests and the maintenance of privileges. Likewise, the elitist structure, which sought shelter in supposed neutrality, was considered by Hélio Pellegrino not only according to its expression in Brazil, but with an elitist, authoritarian and subservient form of structuring various psychoanalytic institutions around the world, which needs to be rethought, according to the principles of democracy, open to free, critical thinking.

Faced, for example, with the Amílcar Lobo case, Hélio Pellegrino repeatedly requested a position from the International Psychoanalytic Association (IPA), which only took a stand on the case very late, after he had been expelled and reinstated by court order. Likewise, from Stephen Frosh's (2017) reading, we perceive this case as a particular expression among others in the development of international psychoanalytic institutions. He takes up the examples of the German Psychoanalytic Society (DPG), which responded to the demands of the Nazi regime by removing Jewish analysts from its staff to remove them from the "Goring Institute". This is in addition to the lack of positioning and the collusion of institutions recognized by the IPA in the face of inequality and political repression in a country; raised in a cult of neutrality, with an adaptive and conformist perspective that has nothing to do with the commitment to the social practice of psychoanalysis. This is despite its liberating, historical, democratic and subversive character; and which empties the essence of the radical elements of psychoanalytic thought.

In this regard, Hélio Pellegrino is an important reference for psychoanalysis, not only for the expression of the defense of the relationship between psychoanalysis and democracy in his own practice or as a figure who broke the silence and the adherence to authoritarianism in different institutions, from the critical basis of a psychoanalytic perspective. His importance is largely because of the central focuses of his contribution to psychoanalysis is his critical reflection on the epistemological, conceptual and practical foundations of psychoanalytic theory.

The author addressed social problems, the crisis in the fundamentals of science in the 19th century and the crisis of the principles of psychoanalysis, in most of his writings. For this reason, the epistemological contributions of his writings to the science of psychoanalysis certainly form a collection that is a real source of research for writing.

To further this, I reviewed some elements of the analysis found in his work. The focus is on a reflection on the epistemological foundations of psychoanalytic theory. It is accompanied by a central analysis of the theory of the Oedipus complex, as well as a continuous concern with analyzing the problems that structure Brazilian society, and which contributes to the construction of his reading of the 
Oedipus Complex, the constitution of subjectivity and the social pact, both generally, and in Brazil specifically. As such, his work discusses the explicit commitment of psychoanalysis in transforming the serious social problems faced by Brazil, which are related to the serious structural problems of international capitalism, and which are reflected in the problems of the development of psychoanalytic institutions around the world.

An historical analysis, based on Marxist theory and psychoanalysis leads him to criticize mechanical Marxism and a conformist, apolitical and neutral psychoanalysis that developed in different types and schools of psychoanalytic institutions during Brazil's dictatorial period. His analysis attributes to this tendency, for example, an elitist appropriation of the theory of the Oedipus complex and the conservative view of the function of the law in the sense of maintaining privileges, legitimizing injustice and oppression, disregarding the fact that privilege is prior to the oedipal and social pacts. It builds arguments in order to defend that this appropriation is ideological. It can be interpreted as reinforcing the conservation of the privileges of the ruling class, legitimizing its structural violence, and removes the power of demystification that is part of the essence of the method of psychoanalysis. This is the essence of the radical discovery of the concept of the unconscious, as well as in the conception of the Oedipus complex and of the law as a generator of equality and alterity. In this sense, it develops an analysis of the fundamentals of psychoanalysis and defends the thesis that they structure an ethics of otherness in psychoanalysis, which is incompatible with the defense of neutrality, authoritarianism and arbitrary power.

From this analysis, Pellegrino seeks to think about differences that are definitive for the differentiation between what constitutes an oedipal pact and a humanizing social pact, how the law is structured and what constitutes a pact for perverse power, which is a fundamental differentiation for understanding its historical intra-psychic and social effects. In this context, Pellegrino defends the thesis that psychoanalysis is necessary mode of thinking at the service of equality and justice and that its apolitical position removes its demystifying, liberating and revolutionary character.

The consequences and richness of his interpretation were recognized at a congress in Chile at which the author presented these questions in 1962. However, despite his contribution and the topicality of the questions he had raised, I researched the conclusions found in his work and found that there is not even a study of the author's psychoanalytic writings. In this sense, writing a critique of the silence which surrounds Pellegrino's contribution to and critique of psychoanalysis - within the area of psychoanalytic research, of psychoanalytic criticism, by the psychoanalytic institutions and by Brazilian psychoanalysts leads to raising the questioning of what is silenced, by silencing his contribution. To take this further, I work with the hypothesis that this runs right through the thematic silence around the burning social problems and its capitalist mode of production. This in turn affects even the ideological amnesia of not addressing them from the point of view of psychoanalytic theory, as well as failing to read Freud and his most original discoveries in renowned psychoanalytic institutions. This is in addition to the apparent amnesia of failing to critically discuss the epistemology of psychoanalysis found in academic conservative thinking.

Pellegrino's analysis focuses on why psychoanalytic institutions do not address all of these theoretical, ethical and political issues, going so far as to domesticate psychoanalysis, in a revisionism of abstract universals, transforming it into an ideological and mechanical instrument for the maintenance of privileges and impoverishing its constitutive essence as a mode of critical thinking. For this reason, the author views the task of reflecting on the fundamentals of psychoanalysis as central, since active and passive apoliticism have consequences in the theoretical plane. These consequences include the conceptualization and theorization of psychoanalysis, going so far as to distort its libertarian essence; repressing discoveries, concepts and theorists that structure the core of the psychoanalytic project, with a view to reinforcing revisionism.

\section{Panorama of psychoanalytic production housed at the Casa de Rui Barbosa Foundation}

A brief overview of the author's psychoanalytic production is presented here, including issues, which are presented in my thesis that will be defended by the end of 2021. This presentation is part of it. I spent some time at the Museum of Brazilian Literature, situated in the Casa Rui Barbosa Foundation (FCRB), in Rio de Janeiro, for a period of research into the author's personal files. And the purpose of this study-visit was to analyze the documents that make up the collection of the author's psychoanalytic production. It contains a formidable set of handwritten documents of theoretical, epistemological, practical, cultural, social and political value on psychoanalytic theory foundations and on psychoanalytic institutions.

They allow us to reconstruct and reflect on theoretical discussions within a range of different psychoanalytic institutions during the military dictatorship in Brazil, as well as on some theoretical omissions. This is in addition to being a testament to the tireless work to ensure democracy within these institutions. However, it is a strange fact that 30 years after his death, there is no study on the author's 
body of work in psychoanalysis, contained in this museum, which begs the question of what is silenced by silencing his contribution?

It was a real discovery to see the wealth of this collection and discover the complex web of psychoanalytic writings contained therein. Without intending to exhaust all the possibilities of surveying and analyzing the author's entire archive which deals with various themes in psychoanalysis in an exercise of synthesis, it is possible to demonstrate to the reader the complex web and the richness of psychoanalytic content that is catalogued in different folders in the FCRB's museum of Brazilian literature. The author's files are grouped in folders denominated by: personal correspondence (PC), family correspondence (FC), personal documents (PD), intellectual production (IP), third party production (TP), miscellaneous (VD), Cs and CT.

The miscellaneous documents folder contains statutes and regulations, and the rules of the Rio de Janeiro Psychoanalytical Society (SPRJ) from 1978 to 1983. Other items included: official curriculum (1983); regulations and minutes of the discussions and approval of the Statute of this institution (1983); regulations of the International Psychoanalytic Association (IPA) - according to the decisions of the institution's XXX Congress (1977); a project for the Curriculum Reform Commission of the SPRJ Psychoanalysis Teaching Institute (1983); and a draft proposal to regulate the admission of psychoanalysts to the Social Clinic of Psychoanalysis (n.d.) ${ }^{2}$.

In the personal documents folder there is a complaint from the Public Prosecutor's Office forwarded to Hélio Pelegrino, for inciting the subversion of the political-social order, referring to the year 1969, was also found. In the document, it states that Hélio Pellegrino needed medical care due to threats to his physical integrity and that of his family, as well as certificates on coronary insufficiency and a fracture to his hand, referring to the period from December 1968 to March 1977.

In the archive identified by the acronym CS, there is a vast set of documents of historical, cultural, social and political value about psychoanalytic institutions. ${ }^{3}$ There are documents referring to the letters between Hélio Pellegrino and the Psychoanalytical Society of Rio de Janeiro, concerning the period from 1972 to 1981 . Among them, there is Hélio Pellegrino's request to the psychoanalyst Serge Lebovici for a response regarding the complaints made about Amílcar Lobo and his connection with SPRJ (1981); as well as correspondence in which Lebovici says that Edward D. Joseph will answer him (1981). Calls for SPRJ meetings, proposing that Pellegrino explain complaints about Amilcar Lobo's role as a member of the Brazilian Armed Forces clandestine torture team. There is also a proposal that Hélio Pellegrino and Eduardo Mascarenhas resign before the SPRJ expelled them, rejected by both who justify the incompatibility between psychoanalysis and authoritarianism; Pellegrino's request for the inclusion of the story that led to the exclusion of the institution's scientific calendar, denied by Vitor Andrade. There are letters between the psychoanalyst and the later SPRJ president, Víctor Manuel de Andrade. There is also a reference to the tribunal for witness questioning in the case of Inês Etiene Romeu against Amílcar Lobo (1981).

There are several documents referring to the crisis in the Psychoanalytic Society of Rio de Janeiro, during the period of the military dictatorship. Among them, those who refer to training in psychoanalysis and its stages in SPRJ (1980), those who elaborate and justify the need to reform the institution's Statutes and Regulations (1981); requests to convene an Extraordinary General Meeting; a response to requests for clarification of the reasons for the non-summoning of the assembly by Jacob David Azulay - in which people tortured by the military dictatorship would participate (1986).

There is also a whole set of documents referring to the exclusion of Hélio Pellegrino and Eduardo Mascarenhas from SPRJ's membership; as well as letters co-signed by both. In addition, we find documents written by Pellegrino, which explain this expulsion as linked to the Amílcar Lobo case and its relationship with the SPRJ. In addition to these, we find several SPRJ documents: minutes, internal circulation information, regulations, SPRJ Teaching Commission Resolutions, testimonies by Amílcar Lobo (1981), a list of documents contained in his portfolio, an article on the charges against him, a petition on his connection with the SPRJ and on other matters and their reasons, among other issues.

There is also the civil appeal of the psychoanalyst to the Court of Justice of the State of Rio de Janeiro, whose respondent is the SPRJ; an IPA syndication committee visit confirmation document sent to SPRJ, among other documents related to the period from 1981 to 1982.

Added to these documents are others that express arguments about the incompatibility between authoritarianism and psychoanalysis; correspondences to the director of the Institute of Teaching of Psychoanalysis (IEP) of SPRJ (1981); letters about the difficulties faced by the members of the Debate Forum. A letter signed by Vítor Manuel Andrade, informing the suspension of Ernesto La Porta's membership rights for having signed a letter published in Jornal do Brasil, in 1981. There were some articles on the accusations against Amílcar Lobo, on the apoliticalism of psychoanalytic institutions, on the resistance to Freud, and on currents of psychoanalytic thought in Latin America. And there is a

\footnotetext{
${ }^{2}$ Documents no date (n.d.)

${ }^{3}$ They would allow us to reconstruct and reflect on the relationship between psychoanalytic institutions and authoritarianism during the period of the military dictatorship and on part of the history of the psychoanalytic movement in Brazil. They also form a testimony of tireless work for democracy in psychoanalytic institutions.
} 
document that outlines Leo Cabernite's questions about the psychoanalyst, intended for the SPRJ Ethics Committee. This is in addition to letters from him requesting measures from the same commission in the face of criticism by Hélio Pellegrino (1986).

There is a copy of the process by Werner Walter Kemper with comments (1983); a petition on the Amílcar Lobo case; documents signed by Vítor Manuel Andrade - at the time, president of SPRJ-; Pellegrino's appeals against his SPRJ exclusion. Here we also have a statement justifying his non-acceptance due to the invitation to teach seminars at the institution (1981), a request that it stop ignoring the existence of the Debate Forum and recognize it as an organ of the institution (1981). There is also a request to that president, made by the Debates Forum, about an anonymous letter that labeled Hélio Pellegrino as communist (1981); copies of the Forum Debates bulletins from 1981 to 1983; a letter to the SPRJ Ethics Committee, signed by Hélio Pelegrino; a request made to him, by SPRJ. Letters co-signed by Eduardo Mascarenhas from 1981 to 1982 . We also found a retraction request document from the International Psychoanalytical Association (IPA), after the confirmation of Amílcar Lobo's participation in a torture team. The document (1986) expresses apologies from the IPA for not accepting the complaint of the psychoanalyst Helena Besserman Viana in 1973 about the Amílcar case, communications about the suspension of Ernesto La Porta's rights and criticisms of the participants in the Debate Forum.

Finally, we find in this folder the following articles by Pellegrino (n.d.), referring to the theme: The current SPRJ crisis, consequence and crowning of other struggles (n.d.); The accusations that weigh on Dr. Amílcar Lobo Moreira da Silva (n.d.); Admiral without a helm (n.d.); Against Closed Doors (n.d.); The institutional crisis of SPRJ (n.d.); Documents and History (n.d.); The Disease of the Psychoanalytic Institutions: SPRJ (n.d.); Dr. Amilcar Lobo made clarifying statements to the Folha de São Paulo on 8/2/1981; Dr. Vitor Andrade's circular distributed to colleagues; At a round table at PUC, I denounced the apoliticalism of psychoanalytic institutions (n.d.); at which he spoke of Melanie Klein, of Abraham, of Ferenczi, of Bion (n.d.); The institution is a necessary evil (n.d.); Contribution to an Institutional Analysis of SPRJ: a case study (1981); Truth and Lapse (1987); and (Productive conversation: 8/21/75 - co-signed by Carlos Barreto, Wilson Chebabi, Fábio Lacombe and Jeremiads Lima (1975).

In the folder entitled third-party production, there are clinical case reports, conferences, speeches, essays, dissertations and theses dedicated to Hélio. Lastly, there is the folder catalogued by the archivists as Intellectual Production. It contains 520 pieces of text, most of which are articles and essays; in addition to several other types of writing. The centrality of the analysis runs through different themes. In this folder, 180 items expressly address psychoanalysis as a central theme. ${ }^{4}$

In view of the above, it is considered that the Archives of the Museum of Brazilian Literature are home to a large part of the author's psychoanalytic production. Thus, it is necessary to emphasize the importance of letters and documents for the reconstruction of the biography and part of the history of the psychoanalytic movement in the country. However, in addition to the breadth and depth of this archive, the focus of the thesis study, to which this text is part, was the author's psychoanalytic production, selecting, as an object of study, the subset of the 180 writings that expressly deal with the psychoanalytic theme, which is the folder catalogued and referred to as intellectual production. At the same time, in the face of this complex web of documents, handwritten and typewritten writings by the author, we note the importance of further research on his psychoanalytic production, which is yet to come.

Given the above, far from lamenting a crisis in the foundations of science or psychoanalysis; thinking about it from the perspective of a critical psychoanalytic perspective is essential because it is based on a wide spectrum from foundations of most libertarian psychoanalytic practices to the most conservative and violent ones. Therefore, the author's study opens relevant perspectives because it deals with fundamental issues and problems that are very current but have not yet been overcome.

\section{References}

Frosh, Stephen (2017). "Like Kings in Their Kingdoms": Conservatism in Brazilian Psychoanalysis During the Dictatorship. Revista Political Psychology 38 (4), 591-604

Pellegrino, H. (nd). O tema da nossa mesa-redonda é sexualidade e poder. Hélio Pellegrino Arquivo Hélio Pellegrino. Museu de Literatura Brasileira. Fundação Casa de Rui Barbosa.

Rivera, T. (2017). Desejo de ensaio. In Psicanálise (pp. 11:23 Rio de Janeiro: FUNARTE.

\footnotetext{
${ }^{4}$ They address different thematic sections, for example: the constitution of the subject by otherness, the relationship between psychoanalysis and politics, the apoliticism of psychoanalytic institutions; psychoanalysis, democracy and social transformation; economic-social-political-cultural structuring of Brazil; violence; crime; public figures in the history of the psychoanalytic movement; political personalities; religion; historical phenomena of capitalism; torture; the relationship between oedipal pact and social pact; re-reading treatises on the Freudian Oedipus Complex from a thorough analysis of Sophocles' work - including Oedipus the King, Oedipus in Colono and Antigone; ethics of psychoanalysis; among others.
} 